\title{
Morphology and Elemental Composition of Atmospheric Particles from Mexico Valley by Scanning Electron Microscopy
}

\author{
G. González-Mancera ${ }^{1}$, O. Amador-Muñoz ${ }^{2}$, B.L. Valle-Hernández ${ }^{2}$, G.L. Santos-Medina ${ }^{2}$, A.E. \\ Hernández-López ${ }^{2}$ \\ ${ }^{1}$ Depto. Ing. Metalurgica, Fac. de Quimica, Universidad Nacional Autonoma de Mexico, Mexico D.F., \\ 04510, ggm@unam.mx \\ ${ }^{2}$ Grupo de Mutagénesis Ambiental, Centro de Ciencias de la Atmósfera, Universidad Nacional \\ Autonoma de Mexico, Mexico D.F., 04510
}

Atmospheric aerosol is composed by gases and particulate matter. Both affect the life on the Earth. Particles with aerodynamic diameter $\leq 2.5 \mu \mathrm{m}\left(\mathrm{PM}_{2.5}\right)$ penetrate deep into the repitarory tract and affect the human health [1,2]. Organic compounds of $\mathrm{PM}_{2.5}$ en Mexico Valley have been studied [3], however, their morphology has been less observed. The purpose of this study was to identify the size, morphology and elemental composition of atmospheric particles to identify probable sources. $\mathrm{PM}_{2.5}$ were collected on glass fiber filters covered with Teflon and baked at $180{ }^{\circ} \mathrm{C}$ for $24 \mathrm{~h}$. Samplings were carried out with in high volume sampler twice in April 2011 at five sites: Northwest, Northeast, Center, Southwest and Southeast. Morphology characterization of individual particles were realized with a FESEM JEOL5600 with backscattered electron signal and their chemical composition was done by $\mathrm{x}$-ray microanalysis EDS Oxfford detector. Morphology of particles presented spherical and blade forms, and irregular agglomerates. Composition consisted mainly of oxygen, carbon and silicon; followed from sulfur, calcium, and sodium. The most abundant and frequents metallic elements were aluminum, iron, copper, lead, barium, and zirconium; while with less frequencies were cadmium, tellurium, selenium and arsenic. Presence of oxides iron in spherical forms (Figure 1a) indicated vapors condensation produced by industry like cast iron. Abundant calcium sulphate particles with foliated habit could have been formed in the atmosphere by secondary origin (Figure 1b), spherical particles composed of copper and sulfur (Figure 1c), or silicon and aluminum oxides (Figure 1d), have an anthropogenic origin. In conclusion, there are primary and secondary particles in the atmosphere of Mexico Valley. Those primary sources related mostly with human activities, while those from secondary origin related with photochemical and condensation process. In addition, size and chemical composition of these particles is a risk for the human health, and it is necessary pay specifically attention on them. 

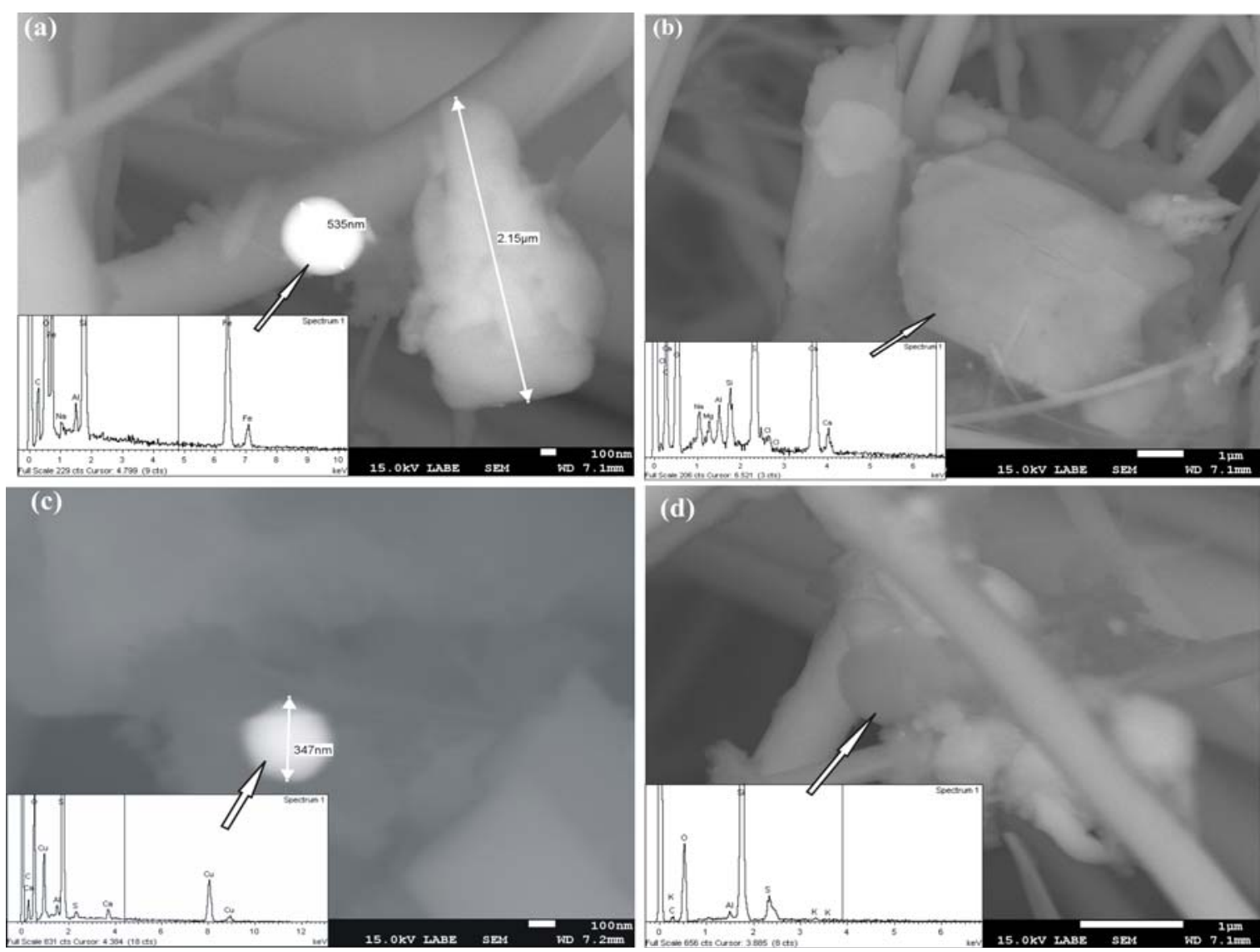

Figure 1. Representative SEM micrographs, and chemical spectrums of atmospheric particles from Mexico Valley. (a) Oxide iron in spherical particle. (b) Particles with foliated habit consisting of calcium sulfate. (c-d) Images of oxides of copper or aluminum respectively, in rounded particles.

\section{References}

[1] A. Aragón-Piña, “¿Cómo son las partículas atmosféricas antropogénicas y cual es su relación con los diversos tipos de fuentes contaminantes?", Ed. Palibrio, USA, p.159.

[2] M. Lazaridis, et al., Environmental Science Technology, 35 (2001), p. 3727-3734.

[3] O. Amador-Munñoz, et al., Science of the Total Environment, 409 (2011) p. 1453-1465. 